\title{
AVALIAÇÃo dE MÉTOdOS PARA DIMENSIONAMENTO DA IRRIGAÇÃO SUPLEMENTAR EM CLIMA ÚMIDO
}

\author{
Álvaro José Back \\ Empresa de Pesquisa Agropecuária e Extensão Rural de Santa Catarina - Estação Experimental de Urussanga \\ SC 446 - Km 16 - Bairro da Estação - Caixa Postal 049 - Urussanga, SC \\ Fone (048) 465-1209
}

\section{Raul Dorfman e Robin Clarke}

Instituto de Pesquisas Hidráulicas, Universidade Federal do Rio Grande do Sul Av. Bento Gonçalves, 9500 Caixa Postal 15029 - CEP 91501-970 Porto Alegre, RS

\section{RESUMO}

A irrigação suplementar tem sido recomendada para as regiões de clima úmido como forma de reduzir os riscos de ocorrência de déficit hídrico; no entanto não existem critérios para o dimensionamento de sistemas de irrigação adequados a essas regiões, sendo utilizados os mesmos critérios desenvolvidos para regiões de clima árido ou semi-árido. Neste trabalho foram comparados os valores de precipitação efetiva determinados pelo método do Serviço de Conservação de Solos dos Estados Unidos e pelos modelos de balanço hídrico horário e diário com os valores de precipitação provável ou dependente. Os diferentes critérios de dimensionamento foram aplicados aos dados da estação meteorológica de Urussanga, SC (28 31' S, 49 19' $\mathrm{W}$, altitude 48,2 m). Os resultados permitiram concluir que a precipitação efetiva média mensal estimada pelo método do Serviço de Conservação de Solo dos Estados Unidos apresenta valores superiores aos valores obtidos pelos modelos de balanço hídrico. A inclusão da metodologia da Curva Número no balanço hídrico diário não resulta em diferença na precipitação efetiva para solos com CN variando de 60 a 90 . O critério de dimensionamento baseado na diferença entre a evapotranspiração média e a precipitação dependente resulta na subestimativa da necessidade de irrigação.

\section{INTRODUÇÃO}

A maioria dos trabalhos relacionados com a irrigação é desenvolvida para atender as regiões que possuem períodos bem definidos com pouca ou quase nenhuma precipitação. Nessas regiões, o projeto de irrigação é dimensionado para atender a todas as necessidades hídricas da cultura, chamado de irrigação total, e o efeito da irrigação na produção é mais previsível, facilitando a análise econômica dos investimentos.

Nas regiões com precipitação distribuída ao longo do ano, o projeto de irrigação deve ser dimensionado de forma a complementar a precipitação natural em alguns períodos e em alguns anos com insuficiente precipitação, isto é, a irrigação deve ser utilizada para cobrir as necessidades hídricas não atendidas pela precipitação natural. Para essas regiões não existem metodologias adequadas para o dimensionamento e manejo do projeto, sendo geralmente empregadas as mesmas técnicas desenvolvidas para as regiões áridas e semi-áridas, o que implica num superdimensionamento do projeto. Como nessas regiões o efeito da irrigação não é tão previsível, por depender da distribuição da precipitação e também pelo fato de geralmente a irrigação proporcionar menor retorno marginal, esses projetos podem não ser lucrativos, principalmente quando não são dimensionados e manejados adequadamente.

O manejo adequado da irrigação deve ser realizado de forma a maximizar o uso da água da precipitação natural, minimizando a irrigação suplementar, tendo como benefícios a economia de energia na captação e condução de água de irrigação, uso de estruturas e equipamento de menor custo e ainda redução nas perdas de solo e nutrientes. Portanto, é de grande importância o conhecimento da contribuição da precipitação natural no atendimento da demanda hídrica das culturas.

Para a prática da irrigação, a "precipitação efetiva" seria a parcela da precipitação total que é utilizada para atender às necessidades da cultura durante o seu desenvolvimento. A quantidade de água necessária para suplementar a chuva efetiva é específica para cada projeto de exploração agrícola, dependendo basicamente do clima, do solo e da planta. Como a precipitação natural é caracterizada pela aleatoriedade e somente uma fração é aproveitada pelas plantas, surge a dificuldade de 
quantificar a precipitação efetiva e de estabelecê-la em termos de risco.

A maioria dos textos de irrigação não aborda com detalhe o assunto de precipitação efetiva, e todas as orientações e recomendações para o dimensionamento e manejo dos projetos são baseados nas metodologias desenvolvidas para a irrigação total. Os técnicos que trabalham na área de irrigação em Santa Catarina têm reclamado da falta de informações que permitam definir a necessidade de irrigação e dimensionar um projeto de irrigação adequado às condições climáticas locais.

Este trabalho teve como objetivo comparar os diferentes critérios recomendados para o dimensionamento de projetos de irrigação suplementar. Foram utilizados os métodos da precipitação dependente e precipitação efetiva determinada pelo método do SCS, tradicionalmente recomendados na literatura especializada em irrigação. Também foi comparado o método da precipitação efetiva determinado pelo balanço hídrico diário e pelo balanço hídrico horário. Com a simulação das relações hidrológicas de forma mais próximas da realidade, o balanço hídrico horário é adotado como referência na avaliação dos demais métodos.

\section{MÉTODOS PARA DETERMINAR A NECESSIDADE DE IRRIGAÇÃO}

Sendo a irrigação suplementar uma forma de complementar a contribuição das chuvas no atendimento das demandas hídricas das culturas, a necessidade de irrigação pode ser estimada com base na probabilidade de ocorrência de chuvas, ou com base no balanço das entradas e saídas de água na camada de solo explorada pelas culturas. O critério da precipitação dependente considera a precipitação provável, enquanto os demais métodos estimam a precipitação efetiva pelo balanço hídrico.

\section{Precipitação dependente}

Vários autores (Doorembos e Pruitt, 1977; Silva et al., 1988; Saad, 1990) recomendam dimensionar o projeto de irrigação com o balanço entre a evapotranspiração e a precipitação com certo nível de probabilidade, sendo indicado geralmente 0 valor médio para evapotranspiração potencial, e o valor da precipitação que é igualada ou superada com certa probabilidade, chamada de precipitação dependente ou precipitação provável.
A necessidade de irrigação pode ser estimada pela relação:

$$
\text { Ir = ETm - PD }
$$

onde: Ir = irrigação; ETm = evapotranspiração máxima; PD = precipitação dependente.

Nesse sentido, foram realizados vários trabalhos (Bernardo e Hill, 1978; Frizzone, 1979; Assis, 1993), determinando a precipitação provável em períodos semanais, decendiais ou mensais. Como a quantidade de água necessária para suplementar a chuva efetiva é específica para cada projeto, dependendo das condições de clima, do solo e da planta, uma simples análise da distribuição probabilística dos totais precipitados parece não ser adequada para o dimensionamento dos projetos de irrigação, podendo subdimensionar a necessidade de irrigação. Embora esse critério inclua o fator de risco, não considera a efetividade da chuva e pode assim subestimar a necessidade de irrigação.

\section{Precipitação efetiva}

O termo precipitação efetiva tem sido interpretado diferentemente não somente por especialistas nas diferentes áreas, como também por diferentes pesquisadores dentro da mesma área de conhecimento. Para a hidrologia de superfície, a precipitação efetiva é a porção da água da precipitação total que escoa superficialmente. Para os hidrogeólogos, a precipitação efetiva é a porção da precipitação que contribui para os aqüíferos subterrâneos. No campo da agronomia, a precipitação efetiva é a fração da água de chuva que atende diretamente às necessidades das plantas, ou seja, é a precipitação total deduzida das perdas por escoamento superficial e por percolação abaixo da zona radicular de uma cultura. expressão:

A necessidade de irrigação é estimada pela

$$
\text { Ir = ETm }- \text { Pef }
$$

onde: Ir = irrigação; ETm = evapotranspiração máxima; Pef = precipitação efetiva.

Hershfield (1964) define precipitação efetiva como a parte da precipitação total durante a estação de crescimento da cultura, que está disponível para o uso consuntivo da cultura, definição semelhante a apresentada pelo SCS (1967). Essas definições não levam em consideração as necessidades de água de uso não consuntivo, como 
necessidade de umidade para o preparo do solo e lixiviação de sais.

Vários fatores influem na proporção da precipitação total que é efetiva, sendo que esses fatores podem atuar isoladamente ou interagir com outros. Qualquer fator que afeta a infiltração, o escoamento superficial ou a evapotranspiração, tem influência no valor de precipitação efetiva. Dastane (1974) descreve o efeito de uma série de fatores na precipitação efetiva.

A avaliação da precipitação efetiva envolve medição da precipitação total e irrigação, das perdas por escoamento superficial, da percolação, além da profundidade do sistema radicular da planta e também da depleção do teor de umidade do solo devido ao componente de evapotranspiração. As informações sobre o tipo de solo, principalmente do perfil explorado pelo sistema radicular, também são necessárias. As medições podem ser feitas direta ou indiretamente, cada componente isoladamente ou de forma integrada.

Hershfield (1964) desenvolveu um nomograma para estimar a precipitação efetiva média durante o período de desenvolvimento da cultura a partir de dados de precipitação média e evapotranspiração média do período e da quantidade de irrigação aplicada. Esses nomogramas foram desenvolvidos usando-se o cálculo do balanço hídrico baseado em dados climáticos de 50 anos de 22 estações climatológicas dos Estados Unidos. Essa metodologia também permite estimar a precipitação efetiva para freqüência diferente da média anual.

\section{Método do SCS}

O Serviço de Conservação de Solos do Departamento de Agricultura dos Estados Unidos (SCS, 1967) desenvolveu o método de estimar a precipitação efetiva, baseado nos mesmos dados utilizados por Hershfield (1964). Foi realizado o balanço simplificado da umidade do solo, considerando-se a precipitação diária e a irrigação como entrada de água, e subtraindo o uso consuntivo. Esse método não considera a capacidade de infiltração do solo, nem a intensidade das chuvas.

O método apresenta ainda outras limitações como o intervalo mensal e também não fornece dados de precipitação efetiva para freqüência diferente da média mensal. Patwardhan et al. (1990) compararam o método recomendado por Hershfield (1964) e o método do SCS (1967) com um modelo de balanço hídrico diário desenvolvido por eles para um solo bem drenado $(\mathrm{CN}=42)$ e para um solo mal drenado $(\mathrm{CN}=90)$. Esses auto- res observaram que ambos os métodos apresentam valores de precipitação efetiva semeIhante ao método do balanço hídrico para o solo bem drenado, porém, superestimaram a precipitação efetiva na condição de solo mal drenado. Também observaram que a precipitação efetiva estimada por esses dois métodos não se ajustou bem com os valores estimados pelo método do balanço hídrico com períodos de retorno superiores a dois anos.

\section{Balanço hídrico}

Com as atuais facilidades computacionais, a metodologia usada para determinar o conteúdo de água no solo e, conseqüentemente, o déficit, é o balanceamento das entradas e saídas de água do solo com a inclusão dos fatores físicos intervenientes no processo. Se todas as peculiaridades dos elementos que influenciam o balanço de água no solo fossem considerados, o balanço se tornaria excessivamente complexo. Esse fato induz a necessidade de serem feitas considerações simplificadoras nos processos envolvidos. Outra limitação no emprego de modelos de balanços hídricos mais complexos é a exigência de informações detalhadas de variáveis climáticas, do solo e das plantas, nem sempre disponíveis.

Uma importante simplificação considerada na maioria dos modelos se refere à infiltração de água no solo. Esse processo é de grande importância prática, pois, quando a velocidade de infiltração é um fator limitante, o balanço de água na zona radicular pode ser drasticamente afetado.

Para o estudo da infiltração da água no solo, quanto menor o tempo de resolução da intensidade da precipitação, maior a precisão da resposta, porém há um aumento do tempo de processamento do modelo. A intensidade de precipitação diária não caracteriza bem a infiltração, e os valores horários situam-se numa faixa de resolução que, além de caracterizar adequadamente o processo de infiltração, não demandam grande tempo de processamento.

Como a grande maioria dos dados meteorológicos existentes no Brasil são de base diária, em geral os modelos de balanço hídrico utilizados não consideram o processo de infiltração, ou consideram de forma simplificada, dado pela quantidade diária de precipitação. O uso desses modelos de balanço hídrico pode superestimar a precipitação efetiva com a conseqüente subestimativa da necessidade de irrigação. Nos locais com chuvas de alta intensidade e com solos de alto potencial de escoamento superficial o modelo de 
balanço também deve estimar de forma adequada o processo de infiltração e escoamento superficial.

Com a utilização de metodologias que permitam desagregar dados de chuva diária em dados horários e dispondo de uma longa série de dados pluviométricos, pode-se proceder o balanço hídrico mais realístico, para avaliar a freqüência da precipitação efetiva e da necessidade de irrigação suplementar.

\section{MATERIAL E MÉTODOS}

Os dados meteorológicos utilizados neste estudo são oriundos da estação meteorológica da Empresa de Pesquisa Agropecuária e de Extensão Rural de Santa Catarina, EPAGRI, localizada na Estação Experimental de Urussanga (latitude $28^{\circ} 31^{\prime} \mathrm{S}$ e longitude $49^{\circ} 19^{\prime} \mathrm{W}$, com altitude de $48,2 \mathrm{~m}$ ), sul de Santa Catarina.

O clima nessa região, segundo a classificação climática de Köeppen, é do tipo Cfa (mesotérmico, úmido e com verão quente). Foi utilizada a série de precipitação pluviométrica total diária do período de 1949 a 1996, e nas demais variáveis meteorológicas foram utilizadas as séries de dados registradas no período de outubro de 1980 a dezembro de 1996.

\section{Precipitação dependente}

A probabilidade da precipitação mensal foi calculada com base no estudo da freqüência dos valores observados, conforme:

$$
F=\frac{m}{n+1}
$$

onde $\mathrm{F}=$ é a freqüência, $\mathrm{m}$ é o número de valores iguais ou inferiores e $\mathbf{n}$ é o número total de observações.

\section{Método SCS}

A precipitação efetiva média mensal pelo método SCS, é estimada pelas seguintes equações:

$$
\begin{gathered}
\text { Pef }=\left(0,70917 P^{0,802416}-0,11556\right) \times \\
10^{(0,02426 E T)} f 25,4
\end{gathered}
$$

onde: Pef $=$ precipitação efetiva mensal $(\mathrm{mm})$; $\mathrm{P}=$ precipitação total do mês $(\mathrm{mm})$; $E T=$ evapotranspiração média mensal $(\mathrm{mm})$;

$$
\begin{gathered}
f=\left(0,531747+0,295164 D^{3}-\right. \\
\left.0,057697 D^{2}+0,003804 D^{3}\right) \\
D=\frac{C A D}{25,4}
\end{gathered}
$$

onde: $\mathrm{CAD}=$ capacidade de água disponível $(\mathrm{mm})$. $\mathrm{Na}$ Equação (3) é imposta a restrição de que a precipitação efetiva não pode exceder a evapotranspiração média mensal, isto é:

$$
\text { Pef } \leq \text { ET }
$$

\section{Balanço hídrico diário}

O modelo de balanço hídrico utilizado segue o modelo de balanço hídrico de Thornthwaite e Mather (1955) modificado por Braga (1982), conforme a seguinte equação:

$$
\begin{aligned}
& \mathrm{ARM}_{(\mathrm{i})}=A R M_{(\mathrm{i}-1)}-E \operatorname{Tr}_{(\mathrm{i})}+\mathrm{P}_{(\mathrm{i})}+\mathrm{Ir}_{(\mathrm{i})} \\
& -\mathrm{R}_{(\mathrm{i})}-\mathrm{Dp}_{(\mathrm{i})}
\end{aligned}
$$

onde: $A R M=$ armazenamento de água no solo no período i $(\mathrm{mm}) ; \quad \mathrm{ETr}=$ Evapotranspiração real $(\mathrm{mm}) ; \mathrm{P}=$ precipitação $(\mathrm{mm}) ; \mathrm{Ir}=$ irrigação $(\mathrm{mm})$; $\mathrm{R}=$ escoamento superficial $(\mathrm{mm}) ; \mathrm{Dp}=$ perdas por percolação profunda $(\mathrm{mm})$.

Foi utilizado o valor de evapotranspiração de referência médio por pentada, calculado pelo método de Penman-Monteith (Smith, 1991; Sediyama, 1996). Para comparação dos modelos de balanço hídrico, considerou-se o coeficiente de cultura $(\mathrm{Kc})$ igual à unidade durante todo o período, o que corresponde ao valor próximo à demanda de pico para a maioria das culturas.

$O$ escoamento superficial $(R)$ foi estimado pelo método da curva número (SCS, 1972), sendo dado pela equação:

$$
R_{(i)}=\frac{\left(P_{(i)}-0.2 S\right)^{2}}{\left(P_{(i)}+0.8 S\right)}
$$

onde: $\quad \mathrm{R}=$ escoamento superficial $(\mathrm{mm})$; $\mathrm{P}=$ precipitação total $(\mathrm{mm}) ; \mathrm{S}=$ capacidade máxima de armazenamento $(\mathrm{mm})$; sendo a capacidade máxima armazenamento de água no solo descrita pela equação: 


$$
S=\frac{25400}{C N}-254
$$

onde: $\quad \mathrm{CN}=$ coeficiente $\quad$ de escoamento (adimensional).

A Equação (7) só é válida quando a chuva total acumulada no intervalo de tempo i for superior a 0,2 S. Caso contrário, não há escoamento superficial.

$\mathrm{O}$ coeficiente $\mathrm{CN}$ é um parâmetro que procura descrever a potencialidade de geração de escoamento superficial do sistema solo-planta. O $\mathrm{CN}$ encontra-se tabelado em função do tipo de solo, uso de solo, da cobertura vegetal, da prática agrícola e do grau de umidade antecedente. O valor de $\mathrm{CN}$ inicialmente atribuído, correspondente a condição de umidade média, foi corrigido em função das condições de umidade antecedentes, determinadas pela aporte de água de chuva ou irrigação nos cinco dias anteriores.

\section{Balanço hídrico horário}

O modelo de balanço hídrico horário proposto segue o modelo do balanço hídrico de Thornthwaite e Mather utilizado em intervalo diário, com as adaptações para a utilização em intervalos horários. As principais adaptações são a inclusão do cálculo da infiltração de água no solo pelo método de Green-Ampt-Mein-Larson para chuvas de intensidades horárias variáveis e a desagregação do valor de evapotranspiração nos intervalos horários com insolação. Para a utilização do modelo, necessita-se de poucas informações adicionais às normalmente usadas no balanço hídrico diário. Além da informação da chuva horária, o modelo requer os valores dos parâmetros da equação de Green-Ampt, que podem ser facilmente estimados em função de características físicas dos solos. As demais informações das características da cultura (Kc e profundidade do sistema radicular) são consideradas constantes durante o dia, pois assumese que, pela pequena variação nos valores diários, as variações horárias podem ser desprezadas.

Os valores de evapotranspiração horária foram calculados assumindo uma distribuição senoidal da evapotranspiração durante as horas do dia com insolação $(\mathrm{N})$. Dessa forma os valores de evapotranspiração são nulos durante a noite, e máximos no intervalo N/2.

A duração da insolação de cada foi calculada para cada dia conforme a equação:

$$
N=\frac{24}{\pi} \arccos (-\tan (\varphi) \tan (\Psi))
$$

onde: $\mathrm{N}=$ duração da insolação $(\mathrm{h}) ; \varphi=$ latitude do local; $\psi=$ declinação solar, estimada por:

$$
\psi=0,4093 \operatorname{sen}\left(\frac{2 \pi}{365} J-1,405\right)
$$

onde $\mathrm{J}$ é o dia do ano [0 a 364].

Os valores de horários de precipitação referente ao período onde somente se dispunha de registros diários foram obtidos pela desagregação destes valores em valores horários seguindo a metodologia desenvolvida por Glasbey et al. (1995).

Como o objetivo do trabalho é determinar a precipitação efetiva, visando ao dimensionamento de sistemas de irrigação, considerou-se a irrigação como entrada de água de modo a elevar a umidade até o nível correspondente à capacidade de campo sempre que o armazenamento de água atingia o limite crítico. Visando ainda a proceder ao balanço hídrico de forma mais próxima às condições de manejo do sistema de irrigação, considerou-se que no modelo de balanço hídrico horário, a irrigação era realizada sempre que a umidade do solo na primeira hora do dia, estivesse abaixo do nível crítico, sendo a lâmina de irrigação definida pelo negativo acumulado somado à evapotranspiração máxima do dia, aplicada nas 8 horas seguintes.

A infiltração foi calculada pelo modelo Green e Ampt modificado por Mein e Larson (1973) com as alterações propostas por Chu (1978), para considerar a chuva de intensidade variável. Em cada intervalo horário em que a intensidade de precipitação é igual ou superior à condutividade hidráulica do solo, é testada a ocorrência de empoçamento durante esse intervalo. Quando esse empoçamento ocorre, deve-se calcular o tempo de empoçamento (tp), a precipitação acumulada até o empoçamento $\left(P_{(t p)}\right)$, o pseudo-tempo (ts) e posteriormente a infiltração acumulada em todo intervalo $\left(F_{(t n)}\right)$. O cálculo da infiltração pode ser resumido pelas expressões abaixo:

$$
\begin{gathered}
t p=\frac{\left[\frac{K s S f M}{(I p-K s)}-P_{(t n-1)}+R_{(t n-1)}\right]}{I p}+t n-1 \\
\mathrm{P}_{(\mathrm{tp})}=\mathrm{P}_{(\mathrm{tn}-1)}+(\mathrm{tp}-\mathrm{tn}-1) \mathrm{lp}
\end{gathered}
$$




$$
t s=\frac{P_{t p p}-R_{(t n-1)}-S f \quad M \ln \left\{1+\frac{\left|P_{(t p)}-R_{(t n-1)}\right|}{(S f M)}\right\}}{K s}
$$

em que: Ks = condutividade hidráulica $(\mathrm{mm} / \mathrm{h})$; $\mathrm{Sf}=$ parâmetro devido ao potencial matricial junto à frente de molhamento $(\mathrm{mm}) ; \mathrm{M}=$ diferença entre a umidade de saturação e a umidade atual $\left(\mathrm{cm}^{3} / \mathrm{cm}^{3}\right) ; \quad$ Ip = intensidade de precipitação; $\mathrm{P}=$ precipitação acumulada até $\mathrm{o}$ tempo $\mathrm{t}$; $\mathrm{R}$ = escoamento superficial acumulado até o tempo $\mathrm{t} ; \mathrm{t}=$ tempo de duração da precipitação $(\mathrm{h})$.

A infiltração acumulada até o tempo tn é determinada pelo método Newton-Raphson na seguinte equação:

$$
K s(t n-t p+t s)=F_{(t n)}-S f M \ln \left[1+\frac{F_{(t n)}}{(S f M)}\right]
$$

O escoamento superficial é dado por

$$
R_{(t n)}=P_{(t n)}-F_{(t n)}
$$

em que: $t p=$ tempo em que ocorre o empoçamento (h); $P_{(t p)}=$ precipitação acumulada até o tempo de empoçamento da superfície $(\mathrm{mm})$; ts = pseudotempo (h).

$\mathrm{Na}$ comparação entre os modelos de balanço hídrico diário e horário, consideraram-se dois valores de CAD, de 50 e $100 \mathrm{~mm}$ respectivamente, e quatro solos diferentes (Tabela 1).

Tabela 1. Parâmetros do solo considerados no modelo de balanço hídrico.

\begin{tabular}{lcccc}
\hline Parâmetro & \multicolumn{4}{c}{ Solo } \\
& A & B & C & D \\
\hline $\mathrm{CN}$ & 60 & 70 & 80 & 90 \\
$\mathrm{Ks}(\mathrm{mm} / \mathrm{h})$ & 7,9 & 4,0 & 1,6 & 0,8 \\
$\mathrm{Sf}(\mathrm{mm})$ & 120 & 165 & 180 & 90 \\
\hline
\end{tabular}

\section{RESULTADOS E DISCUSSÃO}

Os valores de precipitação efetiva média mensal estimados pelo método SCS e pelos modelos balanço hídrico diário e horário, nos diferentes solos, para as capacidades de armazenamento de 50 e $100 \mathrm{~mm}$, constam da Tabela 2. Observa-se que os valores de precipitação efetiva determinada pelos dois modelos de balanço hídrico, nos diferen- tes meses, são em geral inferiores aos valores estimados pelo método SCS.

Para o balanço hídrico diário não há diferença na precipitação efetiva nos diferentes tipos de solo. Esses dados estão de acordo com as observações de Almeida (1993) que encontrou subestimativa insignificante do déficit hídrico, determinado pelo modelo de balanço hídrico diário sem considerar as perdas com escoamento superficial, comparado com os valores determinados pelo balanço hídrico que utiliza a metodologia de repartição do SCS para estimar o escoamento superficial e incluir a precipitação efetiva como entrada no modelo. Isto ocorre porque o método SCS estima o escoamento superficial em função da precipitação total acumulada, e, assim, o escoamento superficial só ocorre quando uma quantidade expressiva da chuva tenha infiltrado. Tendo esses solos valores relativamente baixos de capacidade de armazenamento, a lâmina infiltrada é suficiente para preencher o armazenamento. Assim, as diferenças na quantidade de água infiltrada nos diferentes solos são perdidas por percolação profunda, não diferindo na precipitação efetiva. Sendo a lâmina de irrigação dada pela diferença entre a evapotranspiração e a precipitação efetiva, verifica-se que a diferença na lâmina de irrigação pelo modelo de balanço hídrico diário é inferior a $10 \%$, para solos com $\mathrm{CN}$ variando de 60 até 90 . Dessas observações pode-se concluir que, nas regiões de clima úmido, a inclusão do método de repartição de precipitação em escoamento superficial e infiltração, proposto pelo SCS (1973), na rotina do balanço hídrico, não resulta diferença significativa na estimativa do déficit hídrico, da precipitação efetiva ou da necessidade de irrigação.

O método SCS foi desenvolvido para estimar o escoamento superficial a partir da análise de chuvas de longa duração; por isso, não tem bom desempenho na estimativa do escoamento superficial nos meses de dezembro a março, caracterizados pela maior freqüência de chuvas convectivas, caracterizados por serem chuvas de curta duração e alta intensidade.

Esta observação difere dos resultados obtidos por Patwardhan et al. (1990), que encontraram valores de precipitação efetiva nos solos com baixo potencial de gerar escoamento $(\mathrm{CN}=42)$ muito superiores aos valores obtidos para solos com alto potencial de gerar escoamento superficial $(C N=90)$. Essa diferença pode ser atribuída às diferenças climáticas, pois na região estudada por esses autores, a precipitação média mensal, na maioria dos meses, é inferior à evapotranspiração média mensal, e assim, as perdas 
Tabela 2. Precipitação efetiva média mensal determinada pelos diferentes modelos para Urussanga SC.

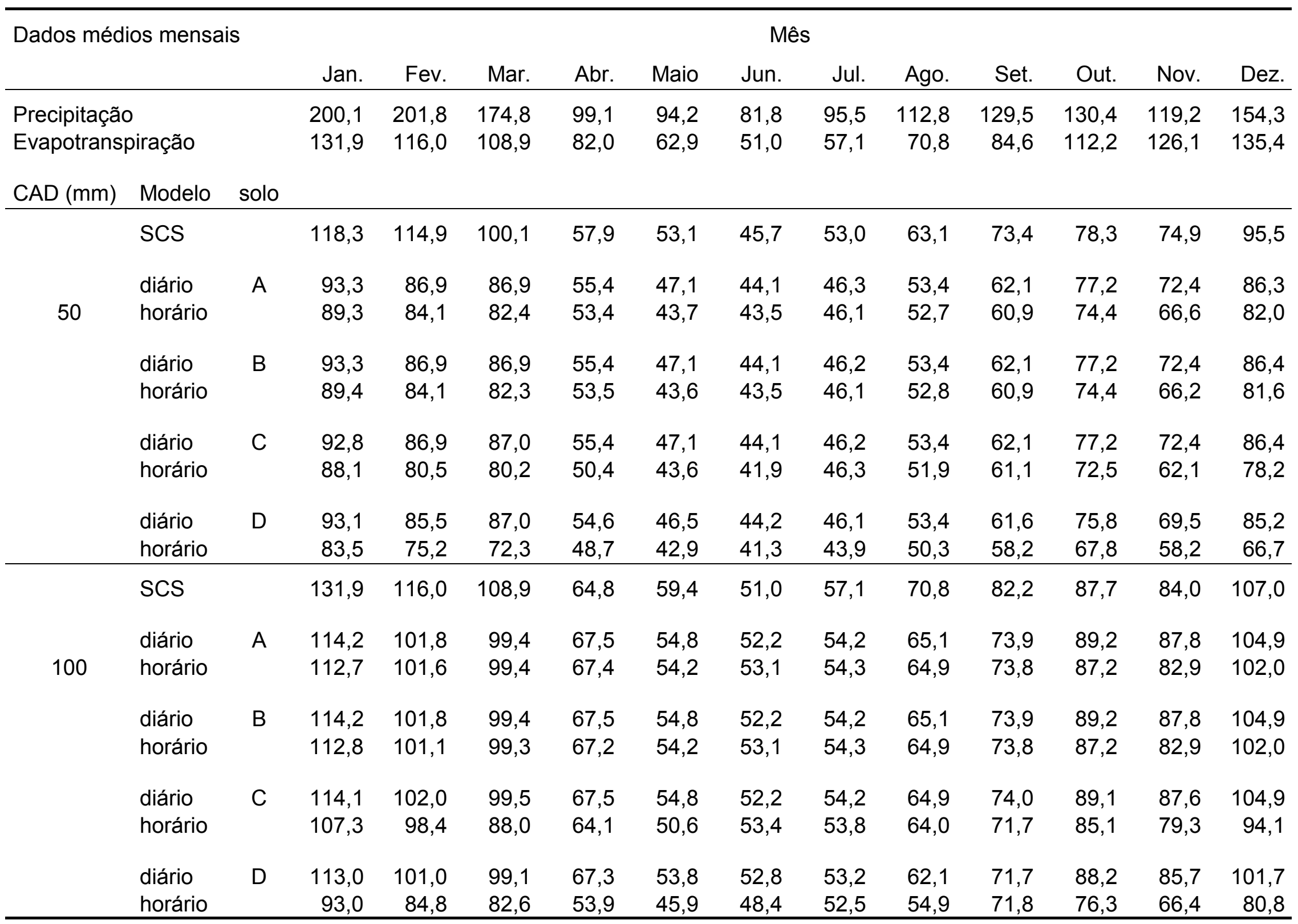


causadas por escoamento superficial se fazem refletir diretamente na redução da precipitação efetiva.

Nos solos A e B, as diferenças entre a precipitação efetiva estimada pelos três modelos é inferior a $10 \%$ nos meses de abril a dezembro. Nos meses de janeiro a março a precipitação efetiva determinada pelo método SCS foi acima de $10 \%$, superior aos modelos de balanço hídrico, sendo que entre os modelos de balanço hídrico não houve diferença. Nos solos C e D, a precipitação efetiva estimada pelo balanço hídrico horário foi inferior aos demais modelos, sendo a diferença mais acentuada nos meses de outubro a março. A maior diferença na precipitação efetiva estimada pelo diferentes modelos de balanço hídrico, ocorre em novembro, quando a precipitação efetiva estimada pelo modelo de balanço hídrico diário foi $29 \%$ superior à precipitação efetiva estimada pelo modelo de balanço hídrico horário, no solo $D$. Isso se explica pelo fato de que, em novembro, a precipitação média é inferior à evapotranspiração média, e, assim, as perdas por escoamento superficial reduzem ainda mais a precipitação efetiva.

Também pode ser verificado que a precipitação efetiva estimada pelo método do SCS, para o solo com CAD $100 \mathrm{~mm}$, é limitada pela evapotranspiração média mensal nos meses de janeiro, fevereiro, março, junho, julho e agosto. Assim, nesses meses, na média dos anos a precipitação pluviométrica atende às necessidades das culturas, não havendo a necessidade de irrigar. No mês de junho, a precipitação efetiva estimada pelos modelos de balanço hídrico diário e horário supera a evapotranspiração potencial, o que significa que parte da precipitação ocorrida no mês de junho é utilizada pelas culturas no mês de julho.

Comparando o valor de evapotranspiração potencial com a precipitação efetiva determinada pelo modelo de balanço hídrico, verifica-se que os maiores déficits ocorrem nos meses de outubro a janeiro, sendo mais acentuados em novembro. Como na região as principais culturas anuais são cultivadas a partir de agosto, verifica-se que estão sujeitas a períodos de deficiência hídrica, que podem variar de acordo com a época de plantio.

Nas Figuras 1, 2, 3, 4, 5 e 6, estão representadas as curvas de freqüência relativa acumulada de precipitação total e da precipitação efetiva determinada pelo modelo de balanço hídrico horário para os solos $\mathrm{C}$ e $\mathrm{D}$, e a precipitação efetiva determinada pelo modelo de balanço hídrico diário para o solo $D$, bem como a precipitação efetiva determinada pelo método do SCS, para os diferentes meses do ano, considerando o solo com capacidade de armazenamento de $100 \mathrm{~mm}$. Nessas figuras foram omitidos os valores de precipitação efetiva determinada pelo modelo de balanço hídrico horário para os solos $A$ e $B$, e também os valores de precipitação efetiva determinada pelo modelo de balanço hídrico diário para os solos $\mathrm{A}, \mathrm{B}$ e $C$, porque não apresentam diferença significativa dos valores de precipitação efetiva determinados pelo modelo de balanço hídrico diário para o solo $\mathrm{D}$.

Com relação à precipitação total, pode-se observar que ela apresenta alta variabilidade nos meses de janeiro a março, nos quais em $20 \%$ dos anos a precipitação mensal supera o valor de $220 \mathrm{~mm}$. Também pode ser observado que, no mês de novembro, a evapotranspiração potencial só é igualada pela precipitação com freqüência acumulada de $62 \%$, o que significa que somente em $38 \%$ dos anos a precipitação total é superior à evapotranspiração potencial. Nos meses de dezembro e abril, o valor da evapotranspiração é igualada pela precipitação com freqüência acumulada de 48 e $40 \%$, respectivamente. Nos demais meses esses valores são inferiores a $30 \%$. Dessa forma, pode-se esperar que a maior freqüência de déficit hídrico ocorra nos meses de novembro e dezembro.

Tomando como base o valor da precipitação efetiva com freqüência acumulada de $20 \%$, o que equivale à precipitação efetiva com período de retorno de 5 anos, observa-se que, no mês de janeiro, a precipitação total é de $115 \mathrm{~mm}$ e a precipitação efetiva determinada pelo modelo de balanço hídrico diário é de $80 \mathrm{~mm}$. Essas diferenças, que representam as perdas por escoamento superficial e percolação profunda, são mais expressivas para os níveis mais altos de freqüência acumulada, e também são maiores no modelo de balanço hídrico horário, quanto maior for o potencial do solo em gerar escoamento superficial.

Nos meses de abril, maio e junho essas diferenças entre a precipitação total e a precipitação efetiva são menos expressivas, principalmente nos níveis mais baixos de freqüência acumulada ou maior período de retorno, o que se explica pela menor intensidade e quantidade de chuvas no período, ocasionando menores perdas por escoamento superficial e por percolação profunda.

Como é comum a utilização de período de retorno de 4 ou 5 anos nos projetos de irrigação e considerando as diferenças entre a precipitação total e a precipitação efetiva, pode-se concluir que a simples análise da distribuição probabilística dos totais precipitados pode superestimar a chuva efetiva, com a conseqüente subestimativa da necessidade de irrigação, sendo essa subestimativa ainda maior, quanto maior for o potencial do solo em gerar escoamento superficial.

Comparando a precipitação efetiva determinada pelos diferentes métodos, verifica-se que a metodologia do SCS apresenta os valores próximos aos valores estimados pelo modelo de balanço hídrico diário para os níveis de freqüência acumulada inferior a $50 \%$. No entanto, nos meses de abril, julho e agosto, a precipitação efetiva estimada pelo método SCS com $20 \%$ de freqüência acumulada, apresenta valores com diferenças acima de $10 \%$ do valor estimado pelo balanço hídrico diário. Nos níveis de freqüência acumulada mais altos, o método do SCS tende a 

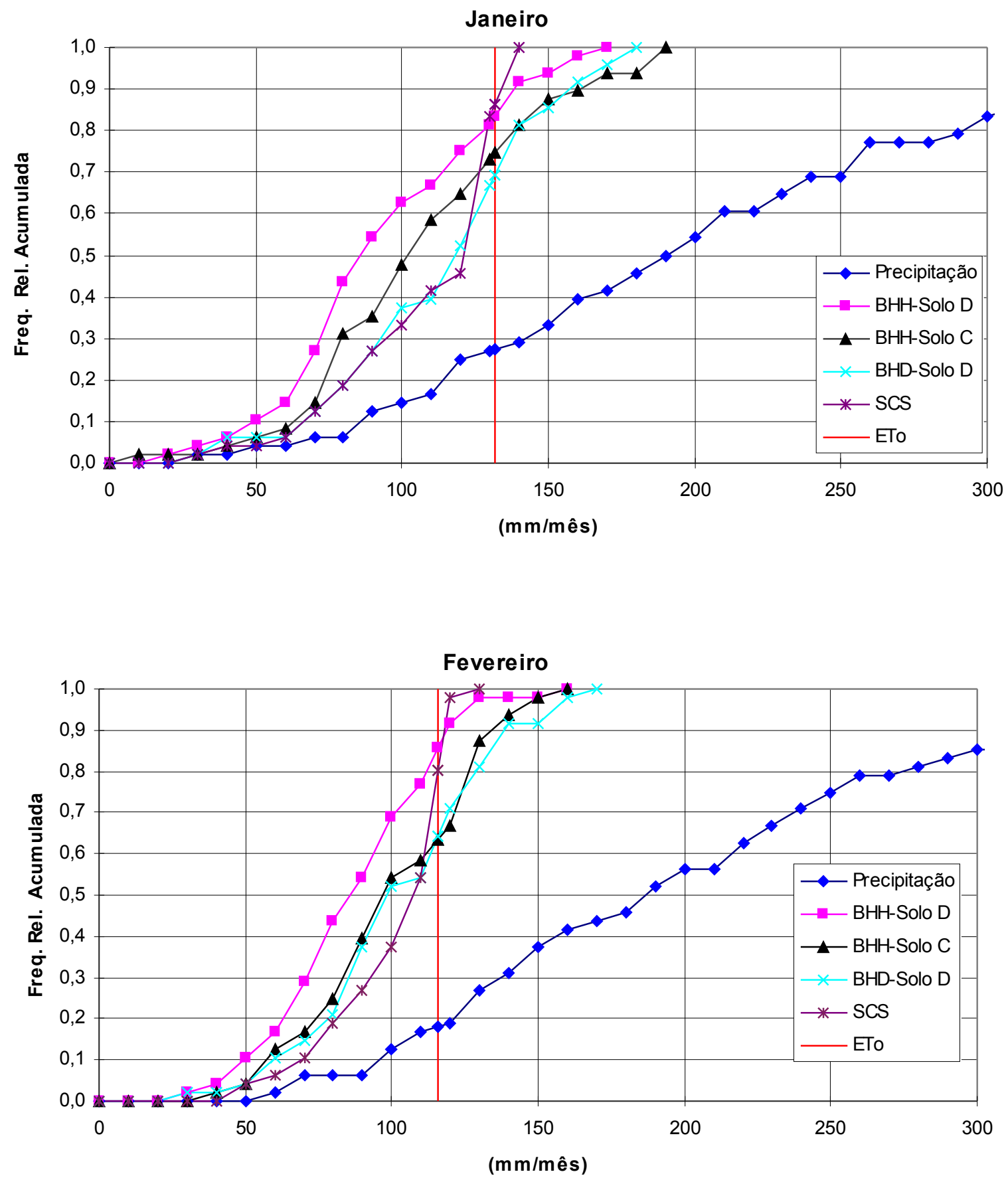

Figura 1. Freqüência relativa acumulada da precipitação total e da precipitação efetiva determinada pelos diferentes modelos para os meses de janeiro e fevereiro. 

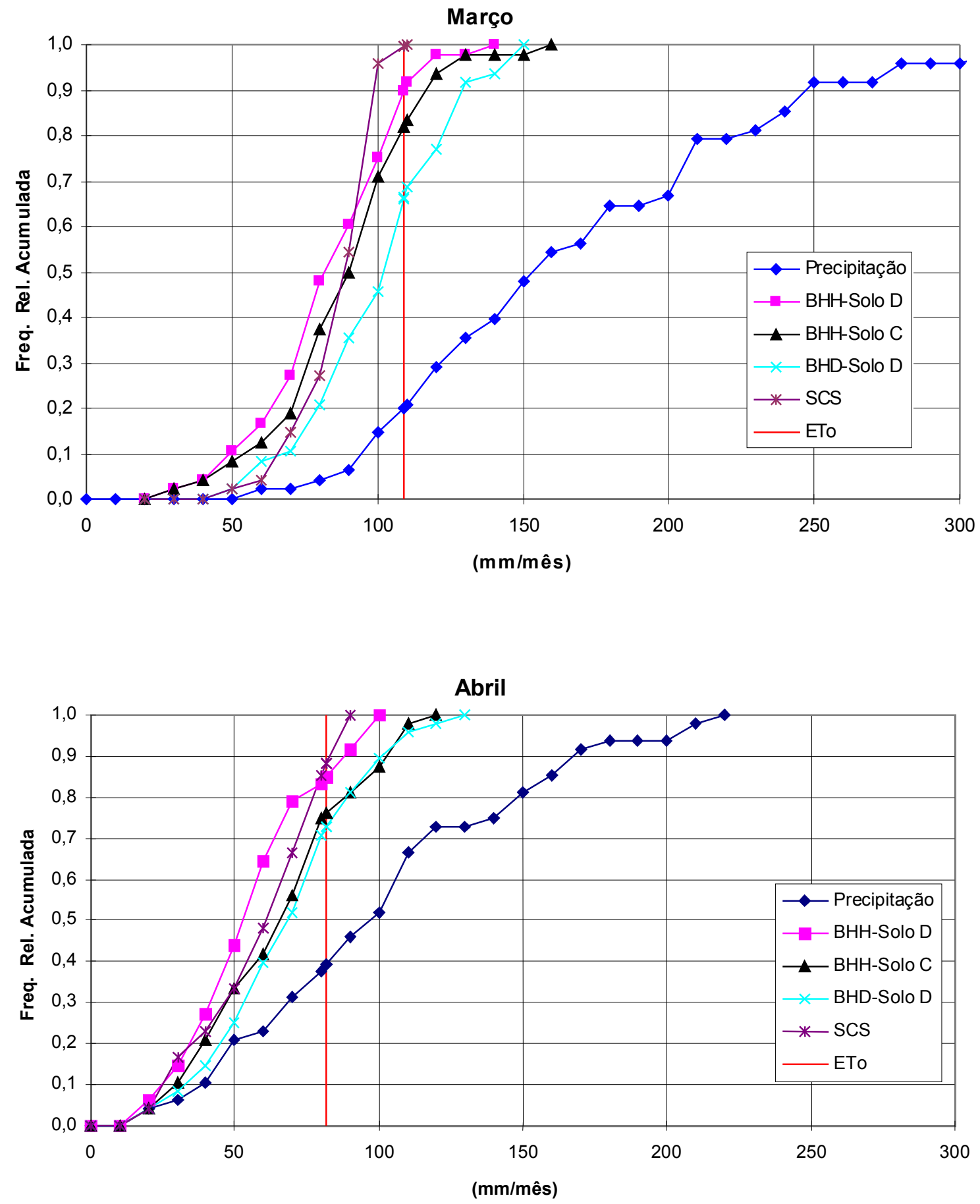

Figura 2. Freqüência relativa acumulada da precipitação total e da precipitação efetiva determinada pelos diferentes modelos para os meses de março e abril. 

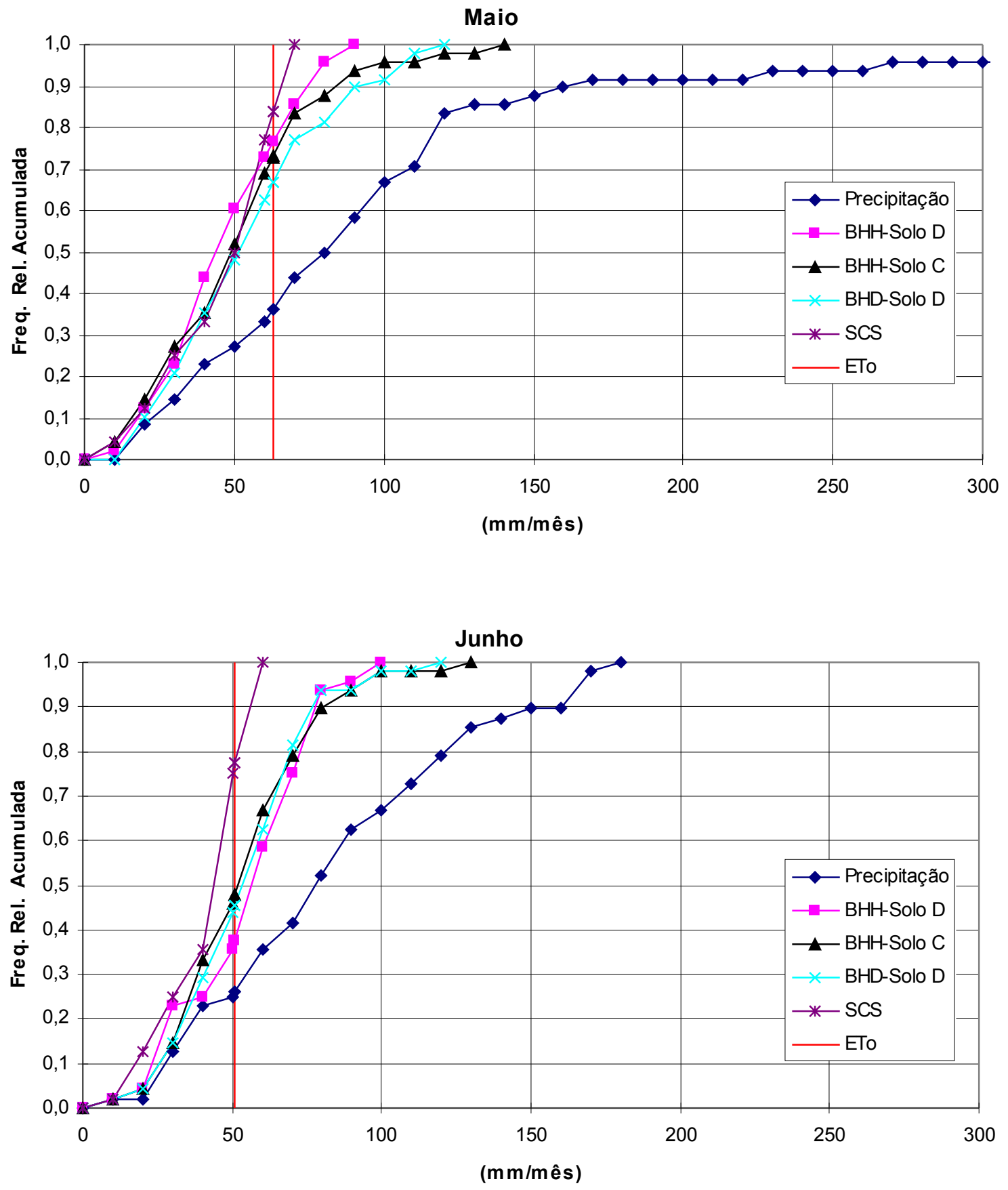

Figura 3. Freqüência relativa acumulada da precipitação total e da precipitação efetiva determinada pelos diferentes modelos para os meses de maio e junho. 


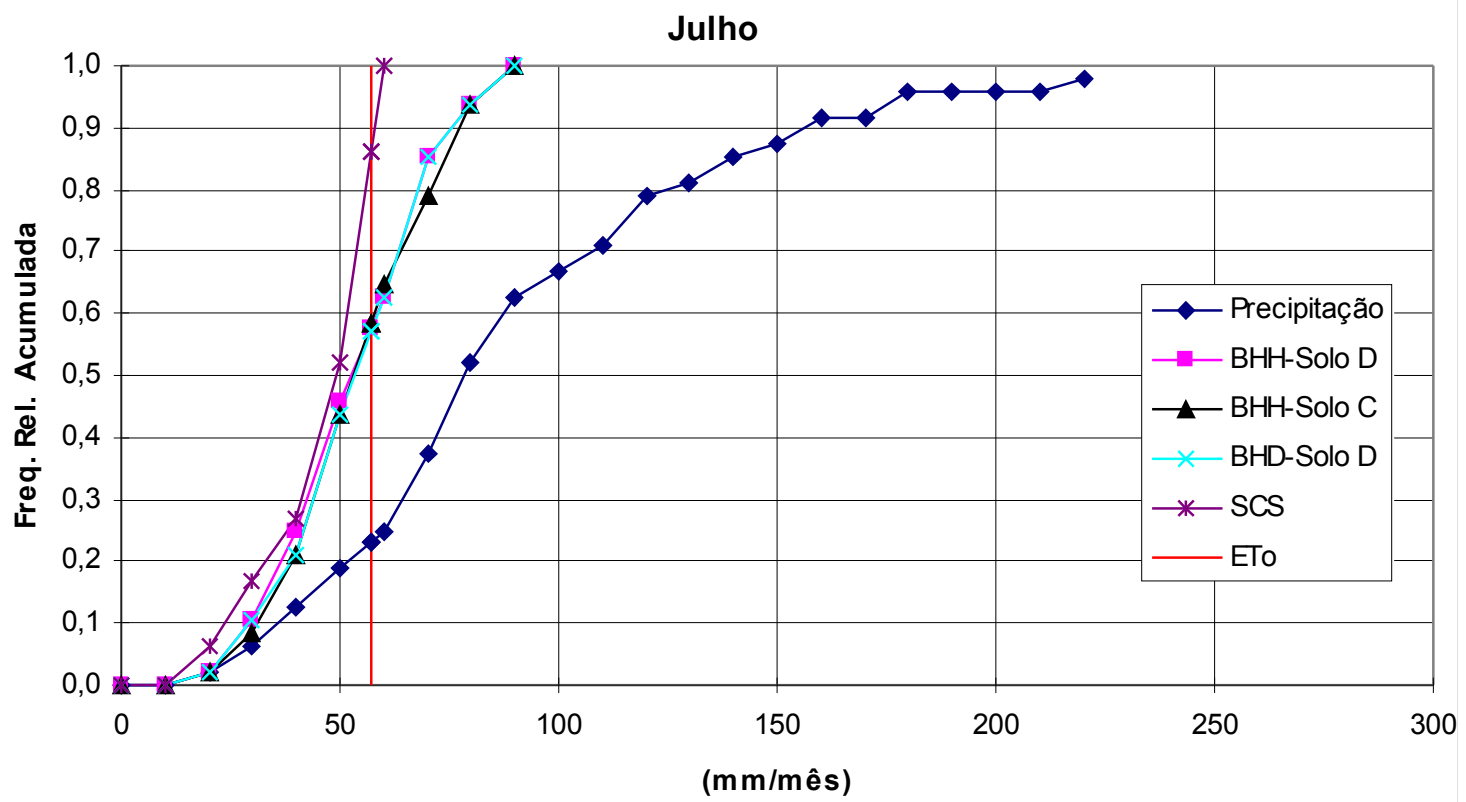

Agosto

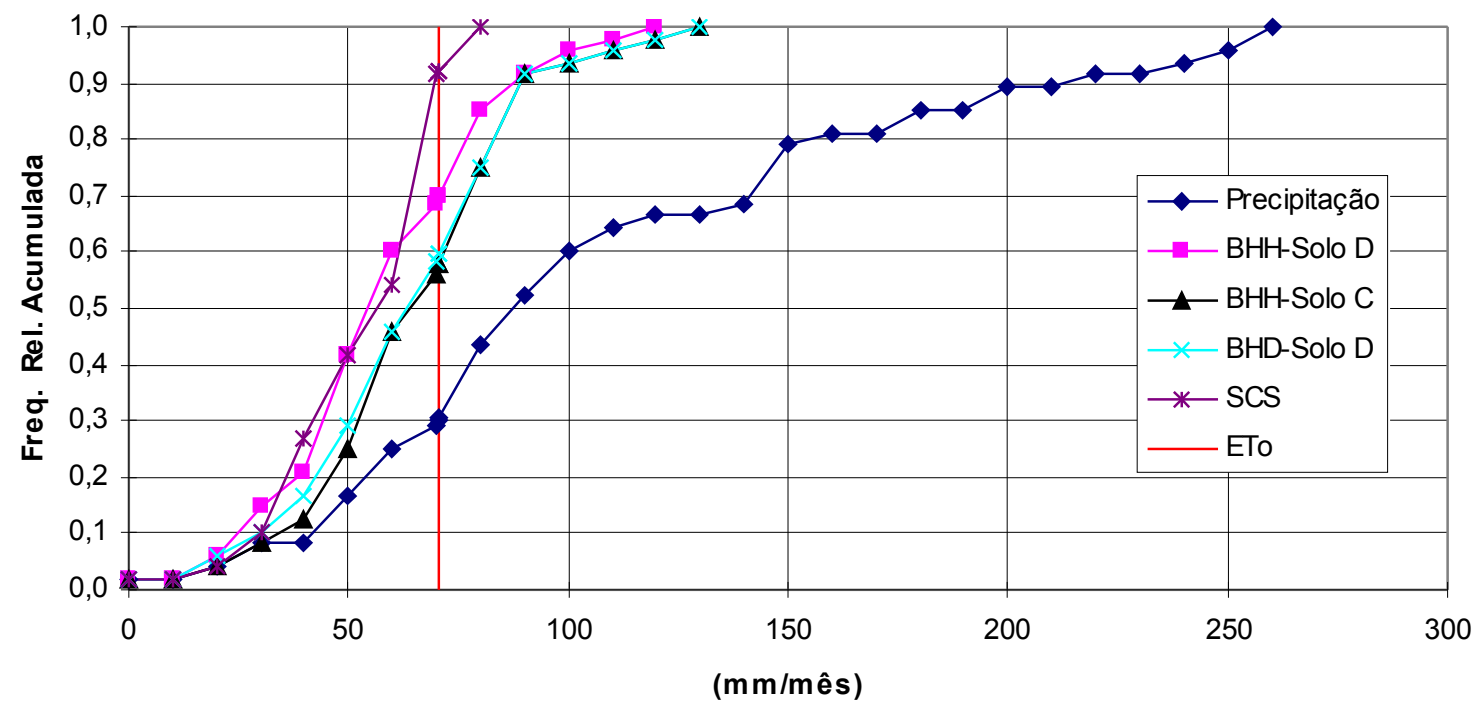

Figura 4. Freqüência relativa acumulada da precipitação total e da precipitação efetiva determinada pelos diferentes modelos para os meses de julho e agosto. 


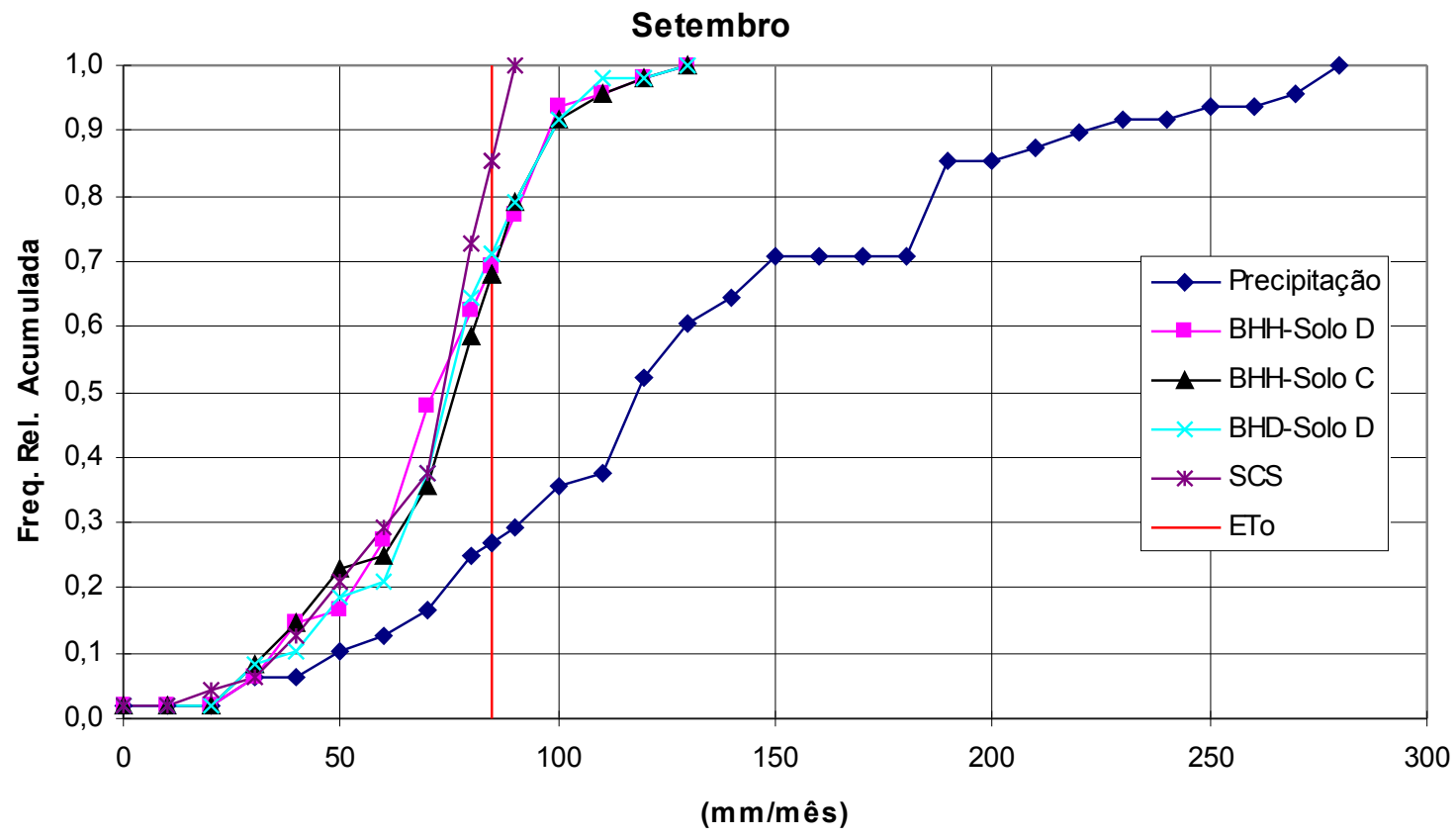

Outubro

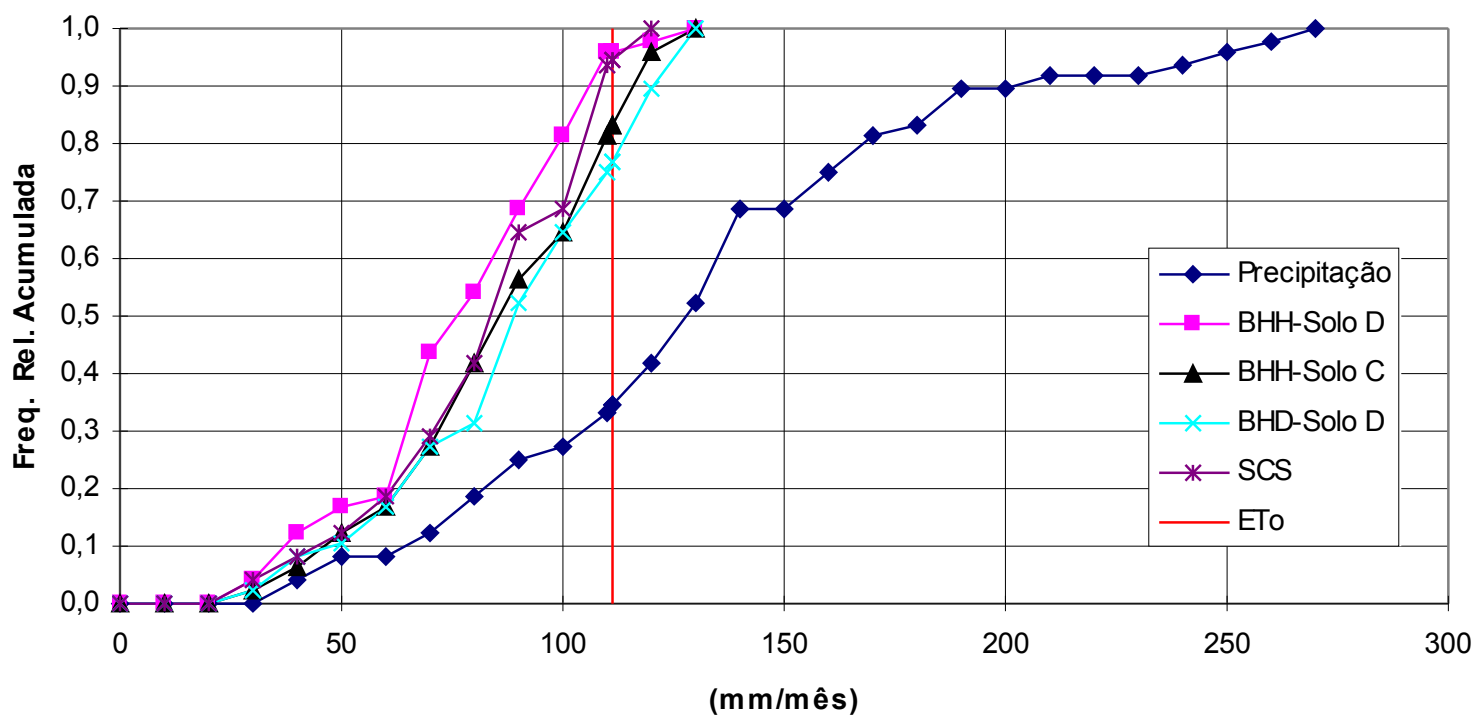

Figura 5. Freqüência relativa acumulada da precipitação total e da precipitação efetiva determinada pelos diferentes modelos para os meses de setembro e outubro. 

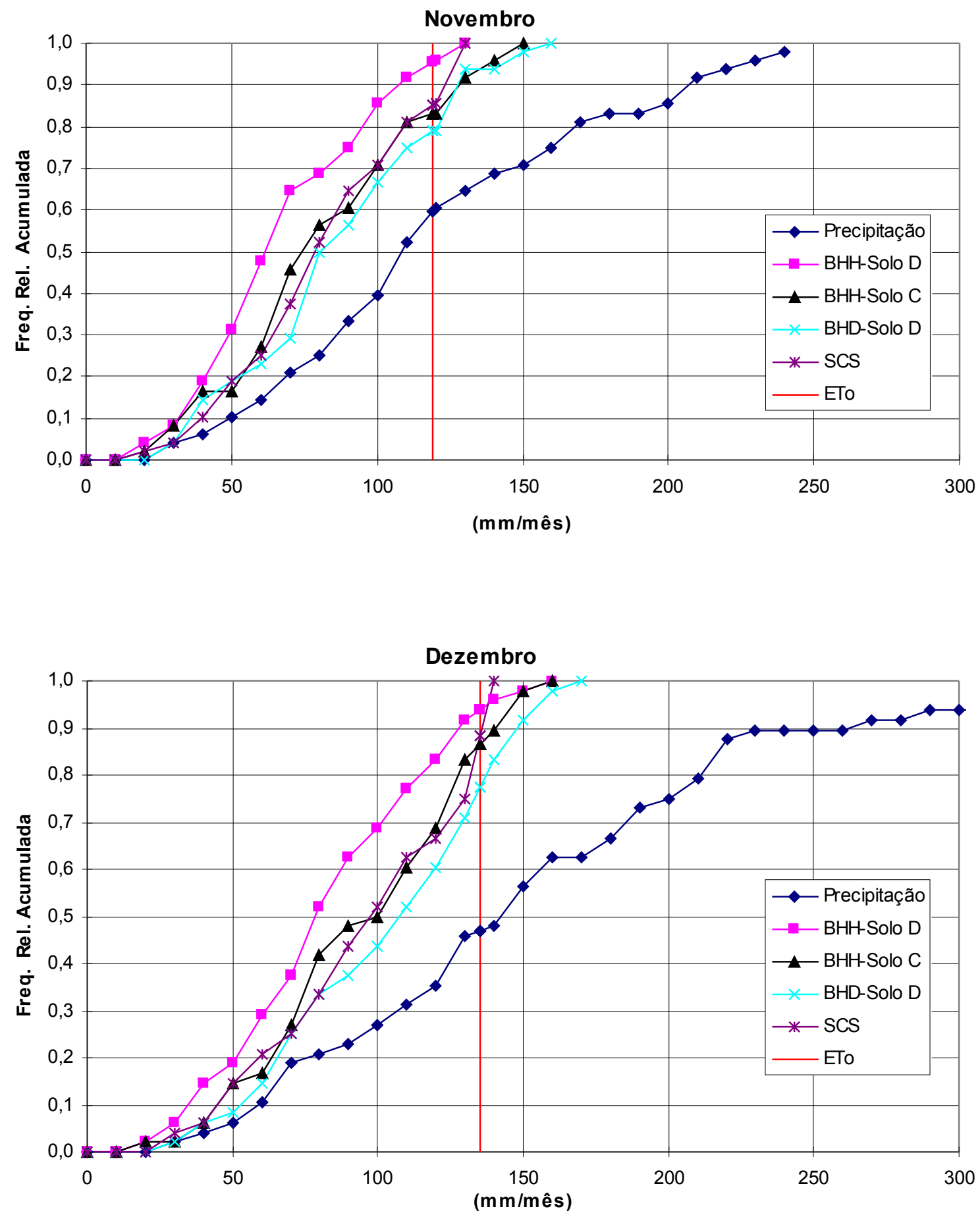

Figura 6. Freqüência relativa acumulada da precipitação total e da precipitação efetiva determinada pelos diferentes modelos para os meses de novembro e dezembro. 
subestimar a precipitação efetiva, devido à restrição imposta da precipitação efetiva ser no máximo igual à evapotranspiração máxima (Pef $\leq \mathrm{ETm})$.

Nos meses de junho, julho e setembro, não há diferença significativa no valor de precipitação efetiva determinada pelo modelo de balanço hídrico horário e balanço hídrico diário, nos diferentes solos, para os diversos níveis de freqüência acumulada, o que se explica pelos baixos valores de escoamento superficial estimado nos períodos. Por outro lado, nos meses de novembro a março, pode-se observar um aumento mais expressivo no valor de precipitação efetiva, quando determinada pelo modelo de balanço hídrico horário para o solo $\mathrm{C}$ em relação ao solo $\mathrm{D}$. Essas diferenças ocorrem principalmente pela diferença nos valores estimados de perdas por escoamento superficial.

Considerando os dados do mês de novembro, que é o mês mais crítico para a ocorrência de déficit hídrico, e tomando como base o valor de freqüência acumulada de $20 \%$ dos anos, verifica-se que a precipitação provável é de $69,0 \mathrm{~mm}$. Esse valor pode ser interpretado da seguinte maneira, somente em $20 \%$ dos anos a precipitação no mês de novembro será inferior a $69,0 \mathrm{~mm}$. Pelo critério de dimensionamento dos projetos de irrigação baseado na precipitação provável ou dependente, a necessidade de irrigação é dada pela diferença entre a evapotranspiração máxima e a precipitação provável, sendo de 50,2 mm (119,2-69,0). Pelo balanço hídrico diário o valor de precipitação efetiva no mesmo nível de freqüência é de $54 \mathrm{~mm}$, e para o balanço hídrico horário no solo $D$ a precipitação efetiva é de $40 \mathrm{~mm}$. No solo C, a precipitação efetiva determinada pelo balanço hídrico horário não difere do valor estimado pelo balanço hídrico diário. Considerando como referência o valor de precipitação efetiva determinado pelo modelo de balanço hídrico horário no solo $D$, verifica-se que a metodologia com o uso da precipitação provável superestima a precipitação efetiva em $72 \%$, e o balanço hídrico diário superestima a precipitação efetiva em $35 \%$. Mesmo em solos com baixo potencial de escoamento superficial, a metodologia da precipitação provável superestima a precipitação efetiva em $37 \%$. O mesmo raciocínio pode ser aplicado aos demais meses.

Por essa análise, fica evidente que o dimensionamento dos projetos de irrigação, baseado na diferença entre a evapotranspiração e a precipitação provável, subestima a necessidade de irrigação. Também se pode observar que nos solos com alto potencial de gerar escoamento superficial, a precipitação efetiva estimada pelo modelo de balanço hídrico diário e pelo método do SCS (1967) é superestimada, sendo que essa superes- timativa depende do mês e do nível de freqüência, sendo mais acentuada quanto mais alto for o nível de freqüência acumulada. Outra observação já discutida é que a utilização da metodologia da curva número para solos com $\mathrm{CN}$ igual ou inferior a 90 não resulta em diferença na estimativa da precipitação efetiva.

Para o uso do balanço hídrico horário há necessidade de conhecer os parâmetros da equação de Green-Ampt, que podem ser estimadas pelas características físicas dos solos com relativa facilidade. Como essas características físicas dos solos geralmente são conhecidas e considerando ainda que os parâmetros da equação de GreenAmpt têm significado físico, as suas estimativas são mais facilmente realizadas do que a estimativa do valor de $\mathrm{CN}$. A dificuldade geralmente apontada para utilização de modelos de balanço hídrico em intervalos de tempo menores, é o maior tempo computacional necessário para processar o modelo, porém, com as atuais facilidades da informática, esse esforço computacional necessário para o processamento do balanço hídrico em intervalos horários não deve mais ser apontado como limitação para a sua utilização. Dessa forma, nos solos com maior potencial de gerar escoamento superficial, recomenda-se a utilização do modelo de balanço hídrico horário para a determinação mais realística da necessidade de irrigação.

\section{CONCLUSÕES}

Com base na discussão dos resultados obtidos, pode-se relacionar as seguintes conclusões gerais para as regiões de clima úmido:

i. o dimensionamento dos projetos de irrigação com base na precipitação provável determina uma expressiva subestimativa da necessidade de irrigação;

ii. a precipitação efetiva média mensal estimada pelo método do SCS (1967) apresenta valores superiores aos valores de precipitação efetiva determinada pelo modelo de balanço hídrico horário, sendo a diferença mais acentuada nos solos com maior potencial de gerar escoamento superficial;

iii. a inclusão da metodologia da curva número do SCS para estimativa do escoamento superficial no balanço hídrico diário não resulta em diferença significativa na estimativa do déficit hídrico e da precipitação efetiva, para valores de $\mathrm{CN}$ igual ou inferior a 90 ; 
iv. nos solos com baixo potencial de gerar escoamento superficial, a inclusão da estimativa de escoamento superficial no balanço hídrico não resulta em diferença na precipitação efetiva;

v. para solos com médio ou alto potencial de gerar escoamento superficial deve-se utilizar o balanço hídrico horário para a determinação mais realística da necessidade de irrigação.

\section{REFERÊNCIAS}

ALMEIDA, J. P. (1993). Estimativa de déficits e excessos hídricos em regiões de clima úmido através de diferentes modelos de balanço hídrico. Porto Alegre: UFRGS - Curso de PósGraduação em Engenharia de Recursos Hídricos e Saneamento Ambiental. $212 \mathrm{f}$. Dissertação (Mestrado).

ASSIS, F. N. (1993). Ajuste da função Gama aos totais semanais de chuva de Pelotas - RS. Revista Brasileira de Agrometeorologia, Santa Maria, v1, p131-136.

BERNARDO, S., HILL, R. W. (1978). Um modelo para determinação de irrigação suplementar. Revista Ceres, v25, n.140. p245-262.

BRAGA, H. J. (1982). Caracterização da seca agronômica através de novo modelo de balanço hídrico, na região de Laguna, litoral sul do estado de Santa Catarina. Piracicaba: ESALQ/USP. p139. Dissertação (Mestrado).

CHU, S. T. (1978). Infiltration during a unsteady rain. Water Resources Research. Washington, v14, n.3, p461-466.

DASTANE, N. G. (1974). Effective rainfall in irrigated agriculture. Rome: FAO. $61 \mathrm{f}$. (Irrigation and Drainage Paper, 25).

DOORENBOS, J., PRUITT, W. O. (1977). Guidelines for predicting crop water requirements. Rome: FAO. p144 (Irrigation and Drainage Paper, 24).

ESTADOS UNIDOS (1967). Soil Conservation Service. Irrigation water requirements. Washington: U. S. Govt. Print. Off. p88. (Technical Release, 21).

ESTADOS UNIDOS (1972). Soil Conservation Service. National Engineering handbook, section 4. Hydrology. Washington: U. S. Govt. Print. Off. Não paginado.

FRIZZONE, J. A. (1979). Análise de cinco modelos para cálculo de distribuição e freqüência de precipitação na região de Viçosa, MG. Viçosa: UFV. p100. Dissertação (Mestrado).
GLASBEY, C. A., COOPER, G., McGECHAN, M. B. (1995). Disaggregation of daily rainfall by conditional simulation from a point process model. Journal of Hydrology, Amsterdam, v165, p1-19.

HERSHFIELD, D. M. (1964). Effective rainfall and irrigation water requirements. Journal of the Irrigation and Drainage. American Society of Civil Engineers, New York, v90, n.2, p33-47, June.

MEIN, R. G., LARSON, R. L. (1973). Modeling infiltration during a steady rain. Water Resources Research, Washington, v9, n.2, p384-394.

PATWARDHAN, A. S., NIEBER, J. L., JOHNS, E. L. (1990). Effective rainfall estimations methods. Journal of Irrigation and Drainage Engineering, New York, v116, n.2, p182-193.

SAAD, J. C. C. (1990). Estudo das distribuição de freqüências da evapotranspiração de referência e da precipitação pluvial para fins de dimensionamento de sistemas de irrigação. Piracicaba, ESALQ/USP, p124. Dissertação (Mestrado).

SEDIYAMA, G. C. (1996). Estimativa da evapotranspiração: histórico, evolução e análise crítica. Revista Brasileira de Agrometeorologia, Santa Maria, v4, n.1, p1-12.

SILVA, W. L. C. OLIVERIA, C. A. S., MOROUELLI, W. A. (1988). Subsídios para dimensionamento de sistemas de Irrigação. In: Congresso Nacional de Irrigação e Drenagem, 8., Florianópolis. Anais. Florianópolis: ABID, v1, p535-553.

SMITH, M. (1991). Report on the expert consultation on revision of FAO methodologies for crop water requirements. Rome: FAO. p45.

THORNTHWAITE, C. W., MATHER, J. R. (1955). The water budget and its use in irrigation. Yearbook of Agriculture, Washington, p346358. 


\section{Evaluation of Methods for the \\ Dimensioning of Supplemental \\ Irrigation in Humid Climates}

\section{ABSTRACT}

Supplemental irrigation has been recommended in wet regions as a way of reducing the risk of water deficiency, although there are no design criteria for irrigation systems applied to these regions, therefore the same criteria developed for arid regions have been adopted. In this study, the effective rainfall values obtained from the American Soil Conservation Service and the hourly and daily water balance models were compared with the values of probable or dependent rainfall. Different design criteria were applied to the meteorological data from Urussanga Station, in the brazilian state of Santa Catarina, I $\left(28,31^{\circ} \mathrm{S}, 49,19^{\circ} \mathrm{W}\right.$, altitude $48,2 \mathrm{~m}$ ). The results, led to the conclusion that the average monthly effective rainfall, estimated by SCS methods, shows values higher than those obtained from the daily and hourly water balance models. The inclusion of the Curve Number method in the daily water balance does not lead to any difference in effective rainfall for soils with a $\mathrm{CN}$ ranging from 60 to 90 . The criterion for dimensioning the irrigation project using the difference between the average evapotranspiration and the probable rainfall, underestimates the needs for irrigation requirement. 